\title{
Immunology of the Lower Respiratory Tract
}

\author{
II. THE PLAQUE-FORMING RESPONSE OF CANINE \\ LYMPHOID TISSUES TO SHEEP ERYTHROCYTES AFTER \\ INTRAPULMONARY OR INTRAVENOUS IMMUNIZATION
}

\author{
H. B. KALtreider, L. Kyselka, and S. E. Salmon \\ From the Pulmonary Disease Group of the Department of Medicine, and the \\ Cancer Research Institute, School of Medicine, University of California, \\ San Francisco, California 94143, and the Section of Hematology and Oncology, \\ Department of Medicine, University of Arizona College of Medicine, \\ Tucson, Arizona 85724
}

A B S T RACT Groups of dogs were immunized with sheep erythrocytes administered either directly into the lower respiratory tract (bronchoalveolar spaces) or intravenously. The hemolytic plaque-forming response (Jerne plaque assay) was studied in various canine lymphoid populations (bronchoalveolar cells, hilar lymph nodes, peripheral lymph nodes, and splenic and peripheral blood leukocytes) as a function of time after immunization and as a function of the dose of antigen administered. Serum hemagglutinating antibody titers against sheep erythrocytes were also measured.

Intrapulmonary and intravenous administration of sheep erythrocytes to dogs both result in an immune response, the kinetics of which are identical to those observed in other animal species. At equivalent doses, the intravenous route is more efficient than the intrapulmonary route in generating serum hemagglutinating antibodies and antibody-forming cells. Both routes give rise transiently to circulating antibody-forming cells during the primary response; the distribution in tissues of antibody-forming cells is distinctive and unique, depending on the route of immunization. After i.v. immunization,

This work was presented in part at the national meeting of the American Federation for Clinical Research, Atlantic City, N. J., April 1973.

Dr. Kaltreider is currently Staff Physician and Chief, Respiratory Care Section, Department of Medicine, Veterans Administration Hospital, San Francisco, California 94121. Part of this work was performed while Dr. Kaltreider was a U. S. Public Health Service Postdoctoral Fellow (HL-05705), and part while he was a recipient of an NIH Special Fellowship (1 FO3 HL-53181-01).

Received for publication 14 December 1973 and in revised form 14 March 1974. antibody-forming cells are found predominately in spleen, blood, and bronchoalveolar spaces; after intrapulmonary immunization, they are located predominately in hilar lymph nodes, blood, and bronchoalveolar spaces. The reasons for this pattern of distribution are not known. Both routes of immunization are equally effective in populating bronchoalveolar air spaces with antibodyforming cells, which are predominately IgM-secreting and IgG-secreting cells. IgA-secreting cells were not detected.

\section{INTRODUCTION}

The bronchoalveolar cell population sampled from pulmonary air spaces by lavage of the normal intact canine lung contains functionally active lymphocytes and macrophages (1). Most immunocytes are bone marrow-derived lymphocytes (B cells), ${ }^{1}$ capable of synthesis of IgG in vitro. Thymus-dependent lymphocytes ( $\mathrm{T}$ cells) are normally undetectable but can be recruited into air spaces by antigenic stimulation. The composition of the lymphocyte population among bronchoalveolar cells differs markedly from that of systemic lymphoid tissue, specifically, lymph nodes, blood, and spleen (1). Because of the method of retrieval and because of the absence of erythrocytes, we believe that the bronchoal-

\footnotetext{
${ }^{1}$ Abbreviations used in this paper: AFC, antibody-forming cell; B cell, bone marrow-derived lymphocyte; MEM, minimal essential medium; PFC, plaque-forming cell; SRBC, sheep erythrocyte; T cell, thymus-dependent lymphocyte.

'H. B. Kaltreider, L. Kyselka, and S. E. Salmon. Unpublished observations.
} 
veolar cell population is derived from peripheral pulmonary air spaces of the lower respiratory tract and from the air side of the pulmonary capillary bed. Thus, we have operationally defined a compartmentalized population of lymphocytes that has an unusual distribution of lymphocyte types (1).

The actual anatomic derivation and the relationship of the lymphocytes in the alveolar compartment to those of the central immune apparatus is unknown. It is uncertain whether the $B$ cells normally present in the lower respiratory tract are static residents capable of an immune response in situ, or whether they are transient cells, a manifestation of the traffic of immunologically committed B cells through the alveolar compartment. Resolution of this fundamental question is essential to an understanding of antibody-mediated immunity in the lower respiratory tract and is central to any definition of a "local" immune response.

Holub and Hauser, using the Jerne plaque assay, originally demonstrated the appearance of specific antibody forming cells (AFC) in alveolar exudates from rabbits immunized with sheep erythrocytes (SRBC) via the intratracheal route (2). Ford and Kuhn confirmed and extended these observations to include soluble as well as particulate antigens $(3,4)$, and found that AFC in rabbit alveolar exudates were predominantly IgMsecreting during the primary immune response and IgGsecreting during the secondary immune response. Nash has recently demonstrated the prompt appearance of IgM-, IgG-, and IgA-producing AFC in hilar lymph nodes of mice immunized with solubilized SRBC membranes instilled into the distal trachea (5).

These studies showed that respiratory immunization can elicit an immune response and that specific AFC accumulate in the alveolar compartment and in regional lymph nodes, but they told us nothing of the origin and fate of these immunologically committed cells. The purpose of our present studies was to characterize the distribution and the concentration in various lymphoid tissues of specific AFC as a function of the route of immunization (intravenous vs. intrapulmonary). We hoped to gain insight into the mechanisms involved in the initiation of the immune response to intrapulmonary immunization and into the accumulation of specific AFC in the alveolar compartment. To provide information relevant to these questions, we determined the time-course of appearance, the distribution, and the concentration of AFC in bronchoalveolar cell populations, local (hilar) lymph nodes, peripheral lymph nodes, spleen, and blood leukocytes as a function of the route of administration of antigen; and we varied the dose of antigen to study the effects on distribution and concentration of AFC.

\section{METHODS}

Animals. Normal adult mongrel dogs of either sex, weighing approximately $15 \mathrm{~kg}$, were used. They were housed in the Animal Care Facility of the University of California, San Francisco, without special precautions.

Experimental design. Groups of dogs were immunized with SRBC either by i.v. immunization or directly into the lower respiratory tract (intrapulmonary immunization). To study the kinetics of the immune response, animals were sacrificed at intervals from 3 to 49 days. Samples of bronchoalveolar cells, hilar lymph nodes, peripheral lymph nodes, blood, and spleen were collected and assayed for AFC by the Jerne, Nordin, and Henry plaque technique (6). Dose-response curves were determined at either 4 or 5 days after immunization, according to the same protocol.

Immunization. SRBC (animal 598, Colorado Serum Co., Denver, Col.) in Alsever's solution were washed with three changes of minimal essential medium (MEM, Grand Island Biological Co., Grand Island, N. Y.) containing $2 \mathrm{U}$ heparin/ml (Lipo-Hepin, Riker Laboratories, Northridge, Calif.) and antibiotics (antibiotic-antimycotic mixture, Grand Island Biological Co.) before use for either immunization or for the hemolytic plaque assay (vide infra). A 20\% (vol/vol) cell suspension in MEM was administered to dogs either intravenously or directly into the air spaces of peripheral lung tissue. The total dose administered was usually $5 \times 10^{10}$ cells but ranged from $5 \times 10^{6}$ to $5 \times 10^{10}$ SRBC.

For intrapulmonary immunization, dogs were lightly anesthetized with intravenous thiopental and secured in the supine position. Immunization was performed through a double-lumen balloon catheter $(1,7)$ wedged into a lower lobe segmental bronchus under fluoroscopic control. The balloon was inflated, gases were removed from the lung segment by aspiration, and a liquid suspension of SRBC was instilled directly into the peripheral air spaces. The catheter was flushed with $5 \mathrm{ml}$ of MEM and left in position for $30-45 \mathrm{~min}$ to allow for the absorption of liquid and the deposition of antigen. The procedure was repeated in the contralateral lower lobe. In independent studies using [25I]SRBC and subsequent determination of tissue radioactivity, we have demonstrated that the vast majority of antigen administered reaches bronchoalveolar air spaces of peripheral lung tissue. ${ }^{8}$

Collection of specimens. Bronchopulmonary lavage was performed in lightly anesthetized animals through a doublelumen balloon catheter $(1,7)$. The bronchoalveolar cells * were collected by centrifugation at $250 \mathrm{~g}$ for $10 \mathrm{~min}$.

Blood was obtained by puncture of the femoral artery. A $10-\mathrm{ml}$ sample was obtained for determination of serum hemagglutinating antibodies. A $40-\mathrm{ml}$ specimen was drawn into a syringe containing heparin (Lipo-Hepin) and allowed to sediment in the presence of $3 \%$ dextran (mol wt 70,000, McGaw Laboratories, Inc., Glendale, Calif.) at room temperature for 30-60 min. The leukocyte-rich supernate was aspirated and the cells collected by centrifugation (200 $g$ for $10 \mathrm{~min})$.

${ }^{3} \mathrm{~F}$. N. Turner and H. B. Kaltreider. In preparation.

4 The nucleated cell population obtained by bronchopulmonary lavage as described previously (1) is referred to as bronchoalveolar cells or, for convenience, as lung cells. It is assumed that this population of cells is a representative sample of immunologically competent cells present in or near air spaces of the peripheral lung. 
The spleen, the bilateral axillary lymph nodes, and the hilar and carinal lymph nodes were obtained by dissection immediately after sacrifice of the dog. The spleen was cut into narrow strips and the cells freed from the fibrous stroma by scraping gently with the blade of a scalpel in a small volume of MEM containing heparin and antibiotics. The cell suspension was allowed to sediment for $10 \mathrm{~min}$ to remove fragments of tissue. The cells in the supernate were collected by centrifugation; hypotonic lysis was used to remove contaminating erythrocytes. Control experiments showed that lysis of erythrocytes did not alter the plaqueforming ability of splenic leukocytes.

The lymph nodes were dissected free of surrounding fat and connective tissue. The hilar and carinal nodes were combined separately from the axillary node pool (peripheral lymph nodes). Cells from the lymph nodes were freed from stroma, tissue debris was removed, and the cells were collected by centrifugation.

Processing of cells. Each of the five cell suspensions from each animal was washed by centrifugation in two changes of MEM containing $2 \mathrm{U}$ heparin/ml and antibiotics. Cells were counted with standard techniques; the cell suspensions were adjusted to $2 \times 10^{2}$ nucleated cells $/ \mathrm{ml}$ and held at $4^{\circ} \mathrm{C}$ until assayed for AFC. Giemsa-stained cytocentrifuge slides preparations were used for differential cell counts. Cell viability, determined by trypan blue exclusion, was usually greater than $90 \%$.

Plaque assay for specific $A F C$. The hemolytic plaque technique described by Jerne et al. (6) was adapted to the dog. All operations were carried out in MEM containing heparin and antibiotics. Portions of the various cell suspensions $\left(2 \times 10^{7}\right.$ nucleated cells $\left./ \mathrm{ml}\right)$ ranging from 50 to $600 \mu \mathrm{l}$ were added to plastic tubes containing $2 \mathrm{ml}$ of molten $0.7 \%$ agar (Difco Laboratories, Detroit, Mich.) $0.1 \mathrm{ml}$ of $1.0 \%$ DEAE-dextran (mol wt 50,000, Pharmacia Fine Chemicals, Uppsala, Sweden), and $0.1 \mathrm{ml}$ of $20 \%$ (vol/vol) washed SRBC (2-3 wk old, Colorado Serum Co.) at $45^{\circ} \mathrm{C}$. The contents of the tubes were mixed by inversion and poured rapidly into plastic petri dishes $(8 \mathrm{~cm}$ in diameter) previously coated with $10 \mathrm{ml}$ of $1.4 \%$ agar (Difco). The soft agar mixture was allowed to gel at room temperature and the petri dishes were incubated for 45 min at $37^{\circ} \mathrm{C}$ in humidified air containing $5 \% \mathrm{CO}_{2}$

To detect direct (IgM) plaques, freshly restored lyophilized guinea pig complement (Grand Island Biological Co.) was diluted 1:10 with MEM and $10 \mathrm{ml}$ was added to each plate. The petri dishes were incubated at $37^{\circ} \mathrm{C}$ for an additional $45 \mathrm{~min}$. To detect indirect (IgG and IgA) plaques, the agar layers were covered with the appropriate rabbit antiserum to dog immunoglobulins for $45 \mathrm{~min}$ at $37^{\circ} \mathrm{C}$; the antiserum was decanted and guinea pig complement added as described above. All assays were performed at least in duplicate.

The agar layers were stained with benzidine hydrochloride-acetic acid-hydrogen peroxide (6), and plaques were counted with the aid of a dissecting microscope. The number of indirect plaques was determined by subtracting from the total the number of direct plaques obtained from parallel assays of cells from the same animal. Results are expressed as plaque-forming cells (PFC) per $10^{\circ}$ viable lymphocytes in each tissue. The background PFC as determined in five control animals $( \pm S D)$ were as follows: bronchoalveolar cells, $1.2 \pm 1.0$; blood leukocytes, $0.77 \pm 0.52$; spleen cells, $1.88 \pm 1.63$; peripheral lymph nodes, $0.42 \pm 0.39$; and hilar lymph nodes, $0.52 \pm 0.25$ plaques $/ 10^{\circ}$ viable lymphocytes.
Antisera. To develop rabbit antiserum specific for the heavy chains of canine immunoglobulins, we used the general method described for the porcine system (8). A polyvalent anti-canine immunoglobulin (anti-Ig) serum was prepared by immunizing rabbits with canine antibody to bovine gamma globulin. The canine antibody (immunoglobulins) had been isolated by affinity chromatography (8). The resulting rabbit antiserum to canine immunoglobulins was not absorbed for light chains and produced an arc by immunoelectrophoresis that was predominately IgG. A 1:200 dilution in MEM of this antiserum was optimal for facilitation of total indirect plaques during the secondary immune response.

Canine IgG was prepared from Cohn fraction II (Sigma Chemical Co., St. Louis, Mo.) by DEAE-cellulose chromatography. The protein eluted with $0.02 \mathrm{M}$ of Tris- $\mathrm{HCl}$ buffer, $\mathrm{pH} 8.0$, was used to immunize rabbits. The rabbit antiserum was absorbed with canine light chains coupled with cyanogen bromide to Sepharose 2B (Pharmacia Fine Chemicals) (8). The resulting antiserum to canine $\operatorname{IgG}$ gave a single arc against whole canine serum by immunoelectrophoresis.

Rabbit antisera to canine $\operatorname{IgA}$ were prepared against purified dog colostral IgA. Two antisera were used. The preparation of a reference antiserum (a generous gift of Dr. John S. Johnson, Scripps Clinic and Research Foundation, La Jolla, Calif.) has been described in detail (9). A second rabbit antiserum was prepared in our laboratory against a canine colostral $\operatorname{IgA}$ that had been isolated by the method of Reynolds and Johnson (9) and further purified by DEAE chromatography. This rabbit antiserum was absorbed with canine IgG and IgM coupled to Sepharose $2 \mathrm{~B}$. The resultant antiserum gave a single arc against both serum and colostrum by immunoelectrophoresis, and yielded a line of identity with the reference antiserum against colostrum by double-diffusion in gel.

Hemagglutination assay for antibodies against $S R B C$. Titers of hemagglutinating antibodies were measured in dog serum with a modification of the microtiter method described by Ammann and Pelger (10). The titer obtained before immunization was subtracted from that obtained after immunization of the same animal; the result is expressed as the reciprocal of the greatest dilution producing agglutination.

\section{RESULTS}

\section{Intrapulmonary immunization}

$Y$ ield and composition of bronchoalveolar cells after immunization. After high-dose $\left(5 \times 10^{10}\right.$ cells $)$ intrapulmonary immunization, the total cell yield obtained by bronchopulmonary lavage rose from our previously determined normal (mean $\pm S D$ ) of $30 \times 10^{\circ} \pm 11 \times 10^{\circ}$ to a peak of $220 \times 10^{\circ}$ nucleated cells at 3 days and returned toward normal values by 5 days after immunization. The percentage of polymorphonuclear leukocytes increased from the normal (mean $\pm \mathrm{SD}$ ) of $2.0 \pm 2.0 \%$ to $25 \%$ at 3 days and fell into the normal range by 5 days. The normal differential value for lymphocytes was $39 \pm 9 \%$ and for macrophages was $59 \pm 9 \%$. After immunization, wide variations in percentage composition were noted, but no trend was detectable. The total num-

Immunology of the Lower Respiratory Tract 


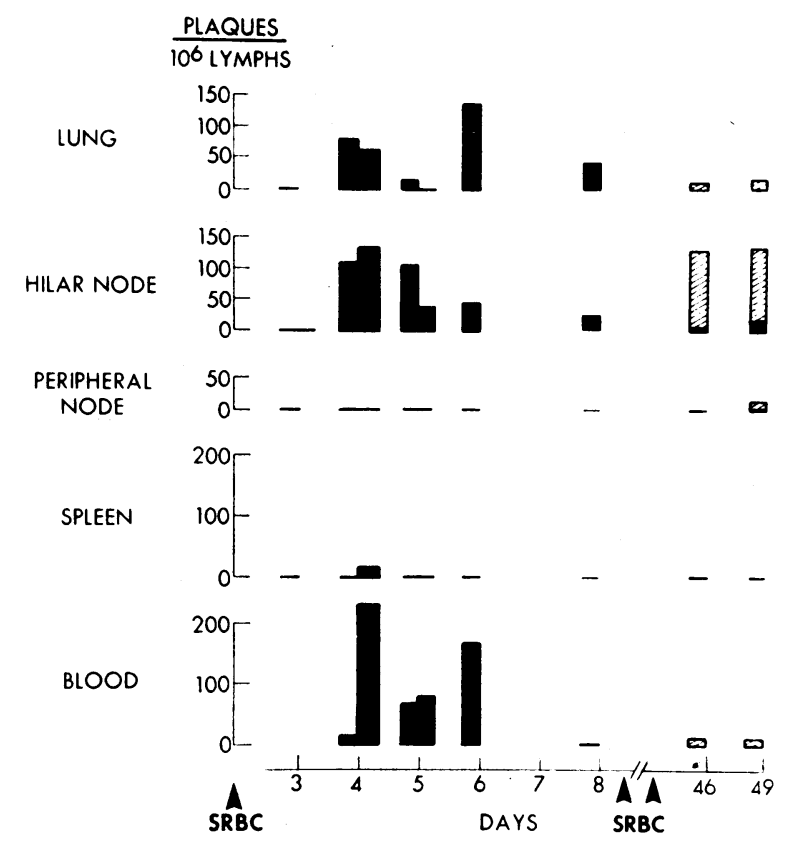

FIgURE 1 Plaque-forming response to SRBC of lymphocytes derived from various canine tissues as a function of time after immunization by the intrapulmonary route. Each vertical column of bars represents the results of a single experiment on one dog. A total of 10 experiments were performed. Solid bars, direct (IgM) plaques; hatched bars, indirect (IgG) plaques. Ig A plaques were not detected in any tissue. SRBC were administered on days 0,12 , and 36 (see text).

ber of lymphocytes and macrophages recovered increased during the 3-5 days after immunization.

Time-course of appearance of $A F C$. The kinetics of appearance, the concentration, and the tissue distribution of AFC after intrapulmonary immunization of 10 animals with $5 \times 10^{10}$ SRBC are shown in Fig. 1.3 days after administration of antigen, AFC were barely detectable in any of the tissues (two experiments). On the 4th day and throughout the primary immune response, direct (IgM) PFC appeared simultaneously among bronchoalveolar cells, hilar lymph nodes, and peripheral blood leukocytes, and were easily detected. Despite their abundant presence in circulating blood, AFC were consistently absent from peripheral lymph nodes and spleen.

Facilitating antisera (anti-Ig, anti-IgG, and anti-IgA) did not amplify plaque formation significantly during the 3-8-day period of the primary immune response.

Late in the secondary response (46-49 days), after two additional intrapulmonary immunizations at days 12 and 36, AFC were detected predominately in the hilar lymph nodes. Few AFC were concentrated in the lung and blood, and virtually none were detected in spleen and peripheral lymph nodes. During the secondary response, we saw more indirect plaques, facilitated by
anti-Ig, than direct plaques. Approximately $75-80 \%$ of the total indirect plaques were IgG-secreting AFC. IgAproducing cells were not detected by either of the two antisera to IgA in any of the cell populations.

Dose response to intrapulmonary administration of $S R B C$. The primary response of AFC to SRBC after intrapulmonary immunization is dose-dependent (Fig. 2). The concentration of PFC in hilar lymph nodes. and blood fell rapidly as the immunizing dose was decreased from $5 \times 10^{10}$ to $5 \times 10^{7} \mathrm{SRBC}$. PFC appeared in the hilar lymph nodes at all antigen doses. Polymorphonuclear leukocytes were not detected in bronchoalveolar cell populations of animals immunized with $5 \times 10^{8}$ SRBC or less, indicating the absence of an acute inflammatory response. PFC were detected in air spaces of the lung only at the highest dose $\left(5 \times 10^{10}\right)$. With a single exception, AFC were not detected in either spleen or peripheral lymph nodes at any dose.

Titers of hemagglutinating antibodies in serum after intrapulmonary immunization. Despite the detection of AFC in the hilar lymph nodes and peripheral blood by the Jerne plaque assay as early as 4 days after immunization, significant concentrations of serum antibodies were not detected by hemagglutination (a relatively insensitive assay) until after the second or third administration of antigen (Fig. 3). The data shown were obtained from

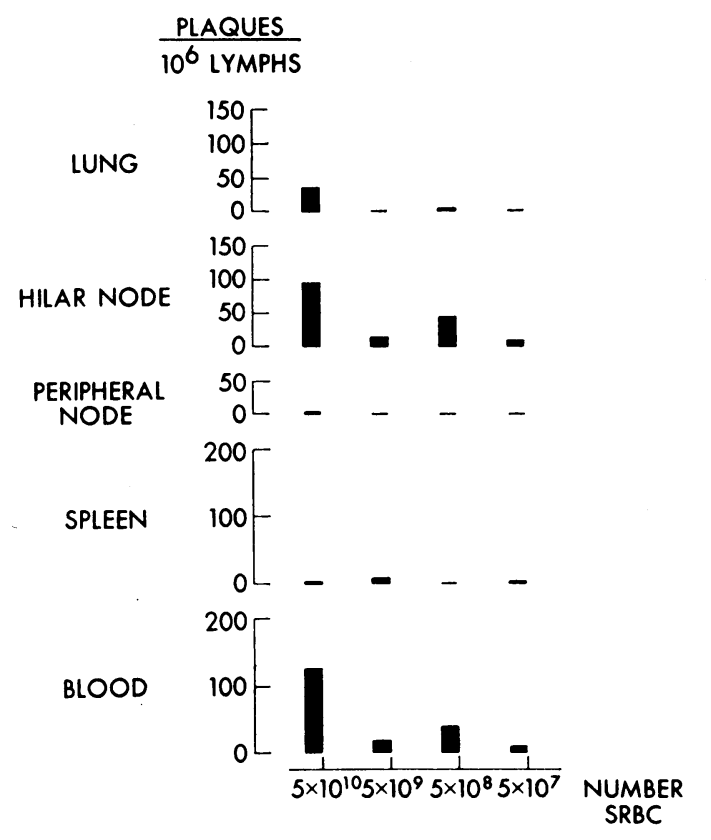

FIGURE 2 Effect on the plaque-forming response of various canine lymphoid tissues of three $\log$-fold reductions in the number of SRBC administered by the intrapulmonary route. Hemolytic plaque assays were performed either 4 or 5 days after immunization. Each vertical column of bars represents a single experiment; four experiments were performed. 
a single dog and are representative of all the animals immunized by the intrapulmonary route in this study.

\section{Intravenous immunization}

Yield and composition of bronchoalveolar cells after immunization. After i.v. administration of $5 \times 10^{10}$ SRBC, the total cell yield obtained by bronchopulmonary lavage remained in the normal range $\left(30 \times 10^{\circ} \pm\right.$ $11 \times 10^{6}$ cells) during the first 5 days and then rose transiently (days 5-7) to $120 \times 10^{6}$. The differential cell count remained normal.

Time-course of appearance and distribution of $A F C$. I.v. administration of $5 \times 10^{10} \mathrm{SRBC}$ to seven dogs resulted in more widespread tissue distribution and higher concentrations of AFC than were observed after intrapulmonary immunization (Fig. 4). A high concentration of AFC appeared in the spleen 4 days after immunization, and these cells were seen throughout the secondary response. During the primary response, AFC were also abundant in blood and among bronchoalveolar cells. In contrast to intrapulmonary immunization, which resulted in the accumulation of AFC in both bronchoalveolar spaces and hilar lymph nodes, i.v. immunization resulted in AFC in bronchoalveolar cells in the absence of large numbers of AFC in the hilar lymph nodes. As with intrapulmonary immunization, peripheral lymph nodes contained virtually no AFC.

Indirect plaques indicative of a secondary response appeared by day 8 . At least $80 \%$ of the total indirect plaques were produced by IgG-secreting AFC. IgAforming cells were not detected. By 14 days after immunization, IgG-secreting and IgM-secreting AFC were concentrated exclusively in the spleen.

Dose response to i.v. administration of $S R B C$. The plaque-forming response of various canine lymphoid tis-

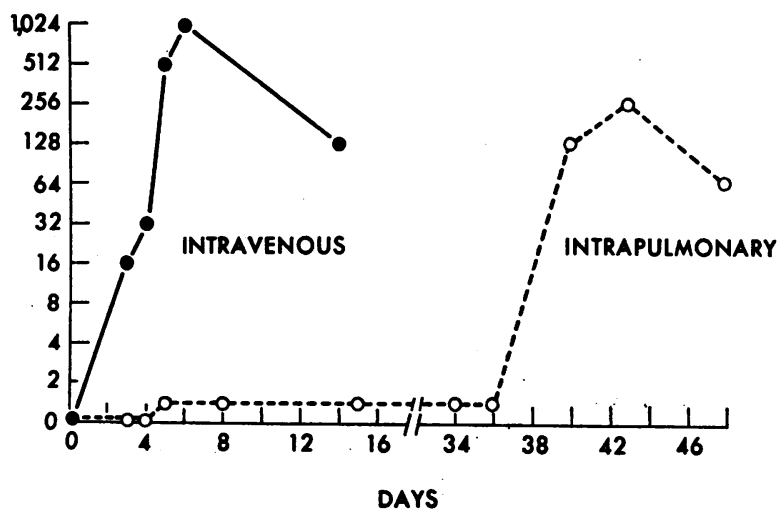

Figure 3 Hemagglutination titers of dog serum against SRBC after immunization. Solid line, antibody response to a single i.v. immunization with $5 \times 10^{10}$ SRBC administered at time 0 ; each point represents a different dog. Broken line, response to intrapulmonary immunization with $5 \times 10^{10}$ $\mathrm{SRBC}$ administered on days 0,12 , and 36 to a single dog.

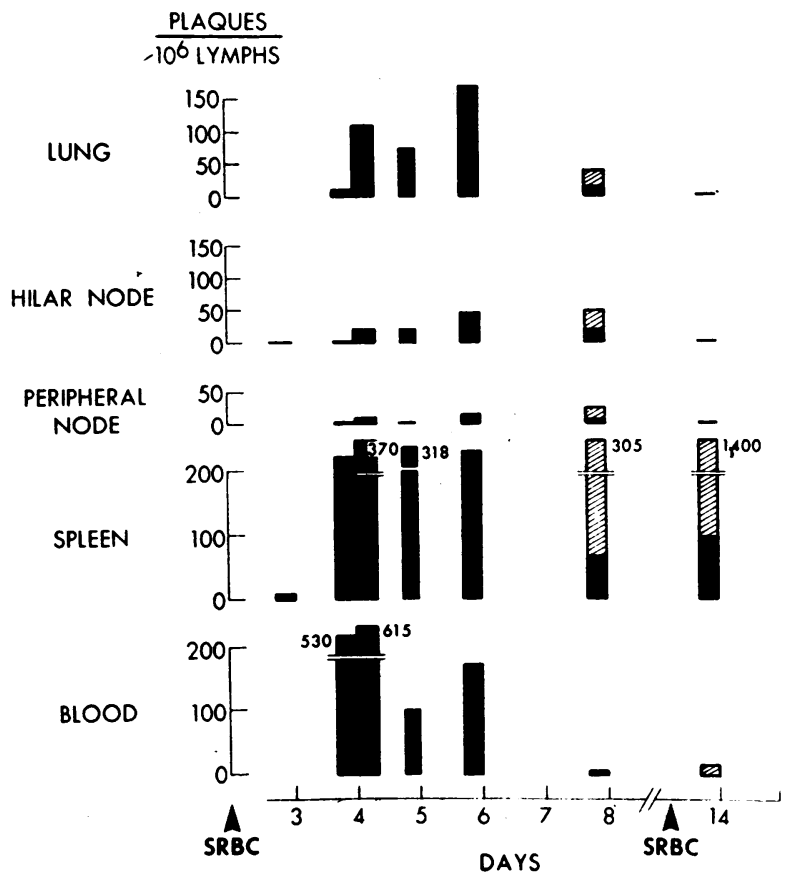

FIgURe 4 Plaque-forming response to SRBC of lymphocytes derived from various canine tissues as a function of time after immunization by the i.v. route. The format of the diagram is identical to Fig. 1. A total of seven experiments were performed. Immunization was performed on days 0 and 12 .

sues decreased in the face of progressive log-fold reductions in immunizing doses of SRBC from $5 \times 10^{10}$ to $5 \times 10^{6}$ cells (Fig. 5). The effect was dose-dependent in all responding tissues. Detectable plaques disappeared completely from bronchoalveolar cell populations and hilar lymph nodes at doses below $5 \times 10^{8}$ cells. Antibodyforming cells were found in spleen and blood over the entire dose range, although their concentrations fell in parallel with each other as the dose was reduced.

Titers of hemagglutinating antibodies in serum after i.v. immunization. In contrast to the low circulating levels of serum antibody resulting from intrapulmonary immunization, hemagglutinating antibody titers were significant at 3 days and peaked at 1/1,024 6 days after intravenous administration of SRBC (Fig. 3). These data were derived from six animals and are representative of our general experience. None of these dogs received a secondary immunization.

\section{DISCUSSION}

The immune response to sheep erythrocytes. The single-cell assay (Jerne plaque assay) employed in our studies was sufficiently sensitive to demonstrate that direct immunization of bronchoalveolar spaces of normal dogs with SRBC results in a primary immune response, 


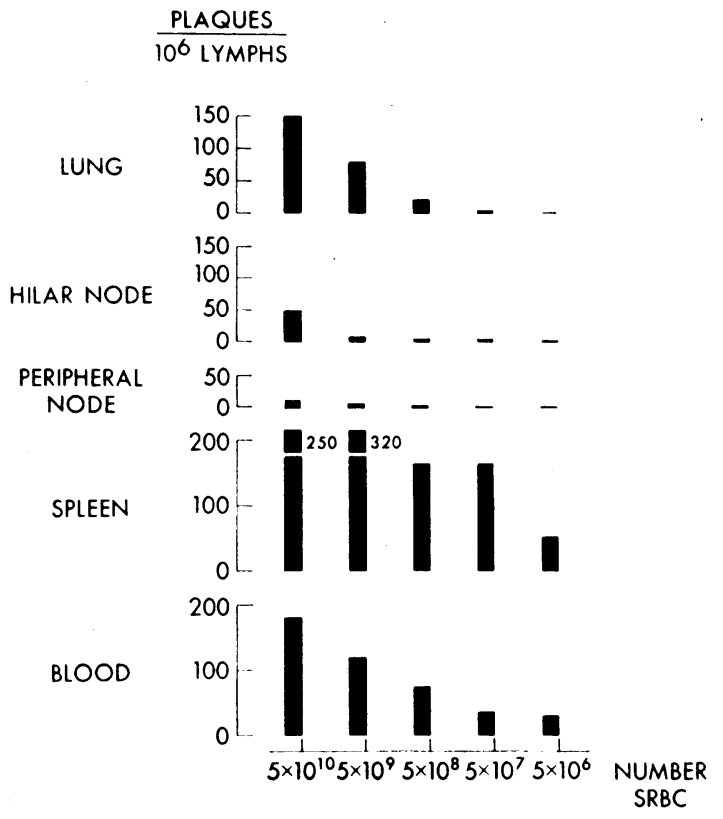

Figure 5 Effect on the plaque-forming response of lymphocytes obtained from various canine tissues of four logfold reductions in the number of i.v. SRBC. Jerne plaque assays were performed either 4 or 5 days after immunization. Each vertical column of bars represents a single experiment; five experiments were performed.

with kinetics identical to those that occur after i.v. immunization: IgM-producing AFC appear first at 3 days, peak at 4-5 days, and gradually subside thereafter. These observations agree with those described for other animal species, including the mouse spleen system (6, $11,12)$.

We found a lag in rise of serum hemagglutinating antibody after intrapulmonary immunization (Fig. 3). The delay suggested that "local defenses" blocked or delayed entry of antigen into central lymphoid tissue. However, our plaque data show that over a wide range of intrapulmonary doses of SRBC, some antigen does gain access to immunocompetent lymphoid tissue and does initiate an antibody-mediated response without a detectable lag in either the afferent or efferent limbs of the immune response. Since AFC and, therefore, antibodies are clearly present in the circulation $4-8$ days after intrapulmonary immunization, the apparent discrepancy between results of the plaque assay and the hemagglutination data is probably best explained by the different sensitivities of the assays and the fact that different types of antibodies are being measured. It appears both from our plaque data (Figs. 2 and 5 ) and from our hemagglutination data that, at equivalent doses, the i.v. route is far more efficient than the intrapulmonary route in stimulating the total body mass of actively secreting AFC formed during the primary response. Thus, the bronchopulmonary tree appears to serve as an imperfect barrier to modest but inflammatory doses of this particulate antigen.

Tissue distribution of $A F C$ after immunization with $S R B C$. A major finding in this study was that the pattern of tissue accumulation of AFC during the immune responses is strikingly different, depending on the route of antigen administration. After intrapulmonary immunization, $\mathrm{AFC}$ are observed in the hilar lymph nodes, blood, and bronchoalveolar spaces, but not in peripheral lymph nodes or spleen. With time, AFC become concentrated in the hilar nodes. After i.v. immunization, AFC are detected predominately in the spleen, blood, and bronchoalveolar spaces. During the secondary response, $\mathrm{AFC}$ are concentrated exclusively in the spleen. The reason for these distinctive patterns of accumulation of $\mathrm{AFC}$ in tissues is not directly discernible from our data.

The observation that intrapulmonary immunization of dogs with SRBC gives rise to AFC in bronchoalveolar spaces and in hilar lymph nodes, but not in the spleen, is in basic agreement with similar results obtained in the rabbit (2-4) and in the mouse (5). Henney and Waldman $(13,14)$ and others $(15)$ have observed a similar phenomenon with respect to $T$-cell functions (migration inhibitory factor) in guinea pig alveolar exudates and spleen cells after respiratory immunization. However, recent evidence indicates that the apparent segregation of the respiratory from the systemic immune apparatus is probably dose-dependent $(15,16)$ and may not hold during the secondary immune response $(5,16)$. Our finding of AFC in circulating blood after intrapulmonary immunization also argues against a strict separation of local and systemic immunity.

$A F C$ in bronchoalveolar air spaces. We found that intrapulmonary immunization and i.v. immunization were equally effective in populating the alveolar compartment with $\mathrm{AFC}$ during the primary immune response. Using animals immunized via the respiratory tract, other workers have also demonstrated the accumulation in alveolar exudates of AFC (2-4) and cells producing migration inhibitory factor (13-16). These workers have generally failed to observe these immunocytes in alveolar exudates after i.v. immunization unless the dose of antigen was very large (15). Although Askonas and Humphrey first demonstrated specific antibody production by isolated rabbit lungs after i.v. immunization (17), their data did not distinguish which cellular components were responsible for antibody synthesis. Our demonstration of AFC, as such, in bronchoalveolar cell populations after i.v. immunization is, to our knowledge, a new observation. We found this phenomenon to be dose-dependent (Fig. 5), and this may explain the discrepancy between our results and those of others. 
The mechanism for generation of AFC in bronchoalveolar spaces is unclear. Collections of lymphocytes are known to exist in the lamina propia of terminal and respiratory bronchioles (18-20), and there is some evidence that lymphoid cells migrate from peribronchiolar lymphatic tissue into air spaces (19). We have assumed that pulmonary lavage samples the peribronchiolar lymphoid tissues. AFC found in bronchoalveolar cell populations, then, likely represent either de novo immune responses occurring in situ in this tissue, responses induced by both routes of immunization, or are the result of traffic of immunologically committed B cells derived from the circulation. Our data do not distinguish between these alternatives.

Major site of $A F C$ production as a function of the route of immunization. One important question to which this study was directed was to determine which lymphoid organ is responsible for generation of an immune response as a function of the route of immunization. After intrapulmonary immunization, AFC appeared simultaneously in bronchoalveolar cells, hilar lymph nodes, and blood. With a reduction in the antigen dose of three orders of magnitude (from $5 \times 10^{10}$ to $5 \times 10^{7} \mathrm{SRBC}$ ), significant numbers of AFC were observed only in hilar lymph nodes and in blood. If we assume that the primary immune response is not generated in circulating blood, the regional (hilar) lymph nodes appear to be the most likely source of circulating specific AFC after small doses of antigen. An immune response could also occur in situ in bronchoalveolar air spaces or peribronchiolar lymphoid tissues. A similar line of reasoning leads us to conclude that, in the dog as in other species, the spleen is the major "target organ" for the initiation and perpetuation of an immune response after i.v. administration of SRBC. The question of whether AFC in bronchoalveolar cells are secondary to their generation in hilar nodes and spleen or whether they arise in situ might be resolved in part by a correlation of the concentration of radiolabeled antigen with the concentration of $A F C$ in various tissues.

Origin and fate of circulating $A F C$. After both i.v. and intrapulmonary immunization, large numbers of AFC were detected in arterial blood on days 4 through 6 of the primary immune response at all antigen doses. If the presence of AFC in arterial blood is assumed to be secondary to their generation in and release from hilar nodes or spleen, it is evident that all lymphoid organs are exposed to circulating AFC by the normal blood flow through their capillary beds. Yet the accumulation of these cells in lymphoid tissues is distinctly not random. Peripheral lymph nodes and spleen are virtually free of AFC after intrapulmonary immunization, and peripheral and hilar lymph nodes contain very low concentrations of $A F C$ after i.v. immunization. There are at least three possible explanations for this phenomenon: (a) circulating AFC preferentially "home" to certain tissues (e.g., those in which antigen is trapped or, perhaps, other tissues not assayed in these studies), (b) AFC are so diffusely distributed and diluted as to be undetectable, or $(c)$ circulating $\mathrm{AFC}$ are dying in the blood stream. Our data do not allow distinction among these possibilities.

The secondary immune response to $S R B C$. Our data relevant to the secondary immune response (indirect plaques) are incomplete. After both i.v. and intrapulmonary immunization, we observed consistently that at least $80 \%$ of amplified plaques, obtained during the secondary response with a polyvalent antiserum to immunoglobulins, were IgG-producing cells. Despite careful study with two independent antisera, we were consistently unable to demonstrate IgA-secreting AFC in any tissues, including bronchoalveolar cells. Thus, with this antigen in this system, IgA-producing cells appear to play a very minor role in the immune response. Since IgA-antibody activity has been demonstrated in upper respiratory mucosal secretions of the dog $(21,22)$, our observations suggest that the bronchoalveolar AFC may be derived from a population quite separate from that which generates secretory immunoglobulins (i.e., cells in the submucosa and lamina propria of medium to large airways). These observations are consistent with those of Ford and Kuhn $(3,4)$ and of Fernald, Clyde, and Bienenstock (23), who observed a relatively weak generation of IgA-secreting cells in the peripheral respiratory tract in response to infection with Mycoplasma pneumoniae.

It is clear that specific $\operatorname{IgA}$ antibody is present in bronchopulmonary lavage supernates $(14,21,22,24$, 25); however, this secretory IgA may well be derived from the respiratory mucosal surfaces of relatively large bronchi. It is not at all clear from the literature that the class-specific antibody composition present in peripheral airways (alveoli and respiratory bronchioles) is identical to that in bronchial secretions. Indeed, recent data suggest that $\mathrm{IgG}$ is the major immunoglobulin class synthesized by peripheral lung tissue in vitro (25).

Conclusions. We conclude that: $(a)$ the intrapulmonary route of immunization effectively initiates a classic primary immune response; $(b)$ at equivalent doses, the i.v. route is more efficient than the intrapulmonary in generating actively secreting $\mathrm{AFC}$; $(c)$ the tissue distribution of $\mathrm{AFC}$ is distinctive and unique depending on the route of immunization and may be determined by the distribution of administered antigen; $(d)$ it appears that the organs predominately responsible for the generation of AFC are the hilar lymph nodes after intrapulmonary and the spleen after i.v. immunization; $(e)$ both routes of immunization are equally effective in populating the

Immunology of the Lower Respiratory Tract 269 
alveolar compartment with AFC; and $(f)$ the bronchoalveolar AFC are predominately IgM-secreting and IgG-secreting cells, and IgA-secreting AFC were not detected.

\section{ACKNOWLEDGMENTS}

The authors thank Dr. Christopher Henney for his helpful suggestions and Dr. John S. Johnson for his generous gift of antiserum to canine $\operatorname{IgA}$.

This work was supported in part by grants CA-11067 and CA 14087-02 from the U. S. Public Health Service, and was aided by grants from the California Research and Medical Education Funds of the California Lung Association, the School of Medicine Committee on Research Evaluation and Allocation (Ackerman Fund), and the Academic Senate Committee on Research (Ethyl Fine Fund and Cook Fund).

\section{REFERENCES}

1. Kaltreider, H. B., and S. E. Salmon. 1973. Immunology of the lower respiratory tract: functional properties of bronchoalveolar lymphocytes obtained from the normal canine lung. J. Clin. Invest. 52: 2211-2217.

2. Holub, M., and R. E. Hauser. 1969. Lung alveolar histiocytes engaged in antibody production. Immunology. 17: 207-226.

3. Ford, R. J., Jr., and C. Kuhn. 1973. Immunologic competence of alveolar cells. I. The plaque-forming response to particulate and soluble antigens. Am. Rev. Respir. Dis. 107 : 763-770.

4. Ford, R. J., Jr., and C. Kuhn. 1973. Immunologic competence of alveolar cells. II. Modification of the plaqueforming response by inhibitors, tolerance, and chronic stimulation. Am. Rev. Respir. Dis. 107: 771-775.

5. Nash, D. R. 1973. Direct and indirect plaque forming cells in extrapulmonary lymphoid tissue following local vs. systemic injection of soluble antigen. Cell. Immunol. 9: 234-241.

6. Jerne, N. K., A. A. Nordin, and C. Henry. 1963. The agar plaque technique for recognizing antibody-producing cells. In Cell-Bound Antibodies.. B. Amos and $\mathrm{H}$. Koprowski, editors. The Wistar Institute Press, Philadelphia, $\mathrm{Pa}$. 109-125.

7. Finley, T. N., E. W. Swenson, W. S. Curran, G. L. Huber, and A. J. Ladman. 1967. Bronchopulmonary lavage in normal subjects and patients with obstructive lung disease. Ann. Intern. Med. 66: 651-658.

8. Kaltreider, H. B., and J. S. Johnson. 1972. Porcine immunoglobulins. I. Identification of classes and preparation of specific antisera. J. Immunol. 109: 992-998.

9. Reynolds, H. Y., and J. S. Johnson. 1970. Canine immunoglobulins. III. Distribution of immunoglobulins in colostrum and isolation of secretory $\operatorname{IgA}$ and $7 \mathrm{~S} \gamma_{1}$. J. Immunol. 104 : 1000-1008.

10. Ammann, A. J., and R. J. Pelger. 1972. Determination of antibody to pneumococcal polysaccharides with chro- mic chloride-treated human red blood cells and indirect hemagglutination. Appl. Microbiol. 24: 679-683.

11. Kotoulas, A. O., and L. A. Moroz. 1971. The direct hemolytic plaque response to hemocyanin in the rabbit. J. Immunl. 106: 1641-1646.

12. Golub, E. S., R. I. Mishell, W. O. Weigle, and R. W. Dutton. 1968. A modification of the hemolytic plaque assay for use with protein antigens. J. Immunol. 100: 133-137.

13. Henney, C. S., and R. H. Waldman. 1970. Cell-mediated immunity shown by lymphocytes from the respiratory tract. Science (Wash., D. C.). 169: 696-697.

14. Waldman, R. H., and C. S. Henney. 1971. Cell-mediated immunity and antibody responses in the respiratory tract after local and systemic immunization. J. Exp. Med. 134 : 482-494.

15. Waldman, R. H., C. S. Spencer, and J. E. Johnson, III. 1972. Respiratory and systemic cellular and humoral immune responses to influenza virus vaccine administered parenterally or by nose drops. Cell. Immunol. 3: 294-300.

16. Nash, D. R., and B. Holle. 1973. Local and systemic cellular immune responses in guinea-pigs given antigen parenterally or directly into the lower respiratory tract. Clin. Exp. Immunol. 13: 573-583.

17. Askonas, B. A., and J. H. Humphrey. 1958. Formation of antibody by isolated perfused lungs of immunized rabbits: the use of $\left[{ }^{14} \mathrm{C}\right]$ amino acids to study the dynamics of antibody secretion. Biochem. J. 70: 212-222.

18. Nagaishi, C. 1972. Functional Anatomy and Histology of the Lung. University Park Press, Baltimore, Md. 153-179.

19. Chamberlain, D. W., C. Nopajaroonsri, and G. T. Simon. 1973. Ultrastructure of the pulmonary lymphoid tissue. Am. Rev. Respir. Dis. 108: 621-631.

20. von Hayek, H. 1960. The Human Lung. Hafner Publishing Co., Inc., New York. 298-314.

21. Lieberman, P., R. Patterson, V. Petersen, L. W. Chakrin, J. R. Wardell, Jr., and J. Ricks. 1971. Effect of antigen variation on production of antibody in canine tracheal secretions. J. Immunol. 107 : 1349-1356.

22. Johnson, J. S., and J. H. Vaughan. 1967. Canine immunoglobulins. I. Evidence of six immunoglobulin classes. J. Immunol. 98: 923-940.

23. Fernald, G. W., W. A. Clyde, Jr., and J. Bienenstock. 1972. Immunoglobulin-containing cells in lungs of hamsters infected with Mycoplasma pneumoniae. J. Immunol. 108 : 1400-1408.

24. Reynolds, H. Y., and R. E. Thompson. 1973. Pulmonary host defenses. I. Analysis of protein and lipids in bronchial secretions and antibody responses after vaccination with Pseudomonas aeruginosa. J. Immunol. $111: 358-368$.

25. Hand, W. L., and J. R. Cantey. 1974. Antibacterial mechanisms of the lower respiratory tract. I. Immunoglobulin synthesis and secretion. J. Clin. Invest. 53: 354 362. 